\title{
Prevalence and associated risk factors of gastrointestinal helminth infection among primary schoolchildren in Dembi district, southwest Ethiopia
}

Awoke Guadie ( $\square$ awokeguadie@gmail.com )

Arba Minch University

Alemu Waji

Arba Minch

Wenzong Liu

Chinese Academy of Sciences

Aijie Wang

Chinese Academy of Sciences

\section{Research}

Keywords: Gastrointestinal helminth, Soil transmitted, Risk factor, School children, Dembi district

Posted Date: January 1st, 2020

DOI: https://doi.org/10.21203/rs.2.19805/v1

License: (c) (i) This work is licensed under a Creative Commons Attribution 4.0 International License. Read Full License 


\section{Abstract}

Background: Gastrointestinal helminths $(\mathrm{GIH})$ are widespread in developing countries including Ethiopia. The prevalence and distribution of GH infection in Ethiopia varies from place to place due to different exposing risk factors. This study aimed to identify the prevalence and associated factors of $\mathrm{GIH}$ infection among primary school children in Dembi district, southwest Ethiopia, where data for helminths infections are previously unpublished.

Methods: A cross-sectional study involving 291 school children in Dembi district were included. Fresh stool samples were collected from each student and examined by direct wet mount using both normal saline and Lugol's iodine preparation and concentration techniques using salt and formol-ether solutions. Questioners and observation were also used to identify socio-demographic and associated risk factors. Data were analyzed using SPSS 20.0 statistical software. $p$-value $<0.05$ were considered significant.

Results: Six parasite species of gastrointestinal helminth with an overall prevalence of $30.9 \%$ were identified. The predominant parasites were found soil transmitted helminth (STH) type including Ascaris lumbricoides (43.3\%), hookworm (26.7\%), Ttrichuris trichiura (8.9\%) and Strongliodes stercoralis (3.3\%). Teania species (6.7\%) and Hymanolepis nana (3.3\%) were also the gastrointestinal parasites detected from the stool samples. The highest prevalence of GIH infection has been observed in the age of 58 years children (36.7\%) followed by 912 (33.3\%) and $\geq 13$ (30.0\%) years. Sex, age, source of water supply and latrine usage has a significant association with GIH infection. Male (37.9\%) students were two times more likely to have parasite infection ( $\mathrm{COR}=2.0,95 \% \mathrm{Cl}=1.173 .22, p=0.011)$ than female $(24 \%)$ students. Comparing age groups, 58 years were more likely to have higher parasite infection (COR=1.23, 95\% $\mathrm{Cl}=0.2330 .797, p=0.007$ ) than older age groups ( 13 years). Those students used stream as a source of water supply and latrine sometimes were also $1.4(p=001)$ and $2.7(p=0.001)$ times more likely to have helminthic infection than students used pipe water and latrine, respectively.

Conclusions: The results of this study showed that GIH infection are important public health problem among primary school children in Dembi district which needs an integrated health control program including periodic de-worming, improving sanitation and safe water provision.

\section{Background}

Parasitic helminths are multi-cellular eukaryotic invertebrates with tube-like or flattened bodies which exhibit bilateral symmetry. The major groups of parasitic helminths include nematodes and flatworms (tapeworms and flukes). The most commonly known helminthic worms are roundworms (Ascaris lumbricoides), whipworms (Trichuris trichiura) and hookworms (Ancylostoma duodenale and Necator americanus), which is collectively called soil-transmitted helminths (STHs) [1]. Adult hookworm inhabit the upper part of the human small intestine, while Ascaris lumbricoides (A. lumbricoides) and Trichuris trichiura ( $T$. trichiura) live in small intestine and large intestine of human gastrointestinal tracts, 
respectively [2]. The parasitic worm eggs are produced in the digestive tract and expelled to the environment with the host's faeces [1]. After a period of maturation in the environment, the parasite eggs hatch as infective larvae in the soil (hookworms) or after ingestion in the intestinal tract (A. lumbricoides and T. trichiura) [1].

The STHs are widely distributed throughout the tropics and subtropics due to favorable climatic conditions as an important factor for their existence and infection [2]. For instance, adequate moisture and warm temperature are an essential environmental for larval development in the soil [3]. Poverty, inadequate water supply, sanitation and poor personal hygiene (especially shoe wearing and hand washing) were also previously reported important epidemiological factor for STHs [1, 4].

Soil-transmitted helminth infections have profound effect on the health of growing children including stunted growth, intellectual retardation, anemia and poor school attendance [5]. These problems are significant in Sub-Saharan Africa (SSA) [4]. Ethiopia is estimated to have the second (26 out of 173 million), third (11 out of 198 million) and fourth highest (21 out of 162 million) burden of ascariasis, hookworm and trichuriasis diseases among SSA countries, respectively $[4,6]$. In terms of national STH prevalence rate in Ethiopia, A. lumbricoides, T. trichiura and hookworm accounted 37,30 and 16\%, respectively [7].

Although several studies have been conducted on the distribution and prevalence of gastrointestinal parasites in Ethiopia [5, 8-13], there are still several localities for which epidemiological information is not yet available [14]. This study was aimed to assess the prevalence and risk factors of GIH infection among primary school children of Dembi district, southwest Ethiopia, where data is limited about helminthes infection.

\section{Methods}

\section{Study area and period}

The study was carried out among three primary school children in Dembi district from December 2014 to May 2015. The district is located $430 \mathrm{~km}$ from Addis Ababa and situated between $8^{\circ} 4^{\prime} 0^{\prime \prime}-8^{\circ} 5^{\prime} 30^{\prime \prime} \mathrm{N}$ latitude and $36^{\circ} 27^{\prime} 30^{\prime \prime}-36^{\circ} 28^{\prime} 30^{\prime \prime} E$ longitude in llu Abba Bora zone, Oromia regional state southwest Ethiopia. The district elevation is also between 1701 and 1827 meters above sea level.

The area annual rain fall ranges from $500-1000 \mathrm{~mm}$, while the minimum and maximum temperature ranged from $15-19^{\circ} \mathrm{C}$ and $23-25^{\circ} \mathrm{C}$, respectively. The main water supply in the district is streams and rivers and in some areas pipe borne supply. In Dembi district, there is only one health center, one private clinic and three primary schools namely Kambo, Tululami and Dembi.

\section{Study population and subject selection}


A cross-sectional study was carried out among primary school children of Dembi distrct. The year 2015 updated list of Kambo, Tululami and Dembi primary schools were the target population of this study. Among 545 male and 655 female students in the three Dembi district schools, a minimum sample size was selected using an appropriate sampling fraction method (Eq. 1).

$$
S=\frac{x^{2} N P(1-P)}{d^{2}(N-1)+x^{2} P(1-P)}
$$

Where $S$ is the required sample size, $x(1.96)$ is the standard deviation at $95 \%$ confidence interval, $\mathrm{N}$ is the total population size, $P$ is the estimated prevalence (50\%) and $d$ is the allowed relative error (0.05) [15]. The minimum sample size after calculation was 291 from the three primary schools including 133, 91 and 67 students from Kambo, Tululami and Dembi schools, respectively.

\section{Data collection and parasitological examination}

In this study, the effect of shoe wearing habits, finger nail statuses, hand washing habits, age and sex as independent variable on the prevalence of $\mathrm{GIH}$ infection as dependent variable were considered.

Questionnaire was used to gather information on socio-demographic and sanitary facilities of students. The study participants were also examined physically for the presence or absence of dirt materials in their fingernails. At the time of the study, the investigator explained about the purpose of the study (students, school administrators and teachers) and asked school children to complete questionnaires that were prepared based on common risk factors of $\mathrm{GIH}$ infection with the help of their teachers.

After the investigator also demonstrated the school children how to collect the sample and handle the samples, they were given a sterile wide mouth plastic containers with screw caps having the appropriate information and identification number. A wooden applicator was also provided to each student. Stool samples for parasitological examination were collected early in the morning before bathing or defecation. In case, if a student couldn't able to collect the morning stool sample by themselves, they were informed to get help from their mothers/guardians. Stool specimens were transported to the laboratory using ice boxes. These specimens were examined by direct wet mount, Lugol's iodine, and formol-ether sedimentation techniques for the presence of intestinal parasites. The samples were first scanned with low power objective (10x) microscopic lens and then switched to 40x objective lens for detail parasitic morphology examination. All specimens were scanned by single investigator to avoid inter-observer error. 


\section{Data analysis}

Data entered into excel and analyzed by using statistical package for social scientists (SPSS) window version 20.0 software. Association of risk factors with GIH parasites was analyzed by using binary logistic regression. Logistic regression model was generated by inclusion of significant independent predictors (socio-demographics, hygienic habits, and others) at the univariate level against the dependent variable (intestinal parasitic infections). Descriptive statistics was also used. The $p$-value $<0.05$ was considered to be statistically significant.

\section{Results}

Among 1200 total students in the three primary schools in Dembi district, 145 (49.8\%) male and 146 (50.20) female students were included in the study (Table 1). A significant $(p=0.011)$ statistical difference were observed in sex for parasitic infection. Male students (37.9\%) found to be 2.0 times more likely at risk (COR=2.0, 95\% $\mathrm{Cl}=1.173 .22)$ than female students (24.0\%).

The age composition of the study participants were ranged from 517 years. The majority $(41.2 \%)$ of the participants were at the age of 13 years, however, the percentage of parasitic infection was found relatively low (22.5\%). Age group 58 years were found to be significantly $(p=0.007)$ at higher risk $(1.2$ times) with parasitic infection than higher age group ( $\geq 13$ years).

Among the total of 291 participants, 90 (30.9\%) participants have been found harboring at least one helminth species (Table 2). Except 7.8\% patients (double infection), most (92.2\%) infections were identified as single infection type (Table 2). A total of six helminths parasitic species were identified including Ascaris lumbricoides, hookworm, Strongliodes stercoralis, Trichuris trichiura, Hymenolepis nana, and Teania species (Table 2). The predominant species were found to be Ascaris lumbricoides (43.3\%) and hookworm (26.7\%) followed by Trichuris trichiura (8.9\%) and Teania species (6.7\%).

Except Strongliodes stercoralis and Teania species, females were infected by three parasitic worms. However, the six parasitic worms were identified in male participants with higher infection rate than females, particularly Ascaris lumbricoides, Trichuris trichiura and Hymenolepis nana. Hookworm was identified in equal proportion from males and females. Moreover, the co-infection also observed in males and females (Table 2). Younger age groups (5 8 years) were found to be more prevalent for Ascaris lumbricoides. However, Hymenolepis nana and Teania species were not detected at lower age groups. Participants at the age group of 912 years were found to be more affected by Trichuris trichiura (83.3\%) and Teania species (62.5\%) than other parasitic species. Relatively, older age groups (>12 years) were also affected by higher proportion of Hymenolepis nana, hookworm and Ascaris lumbricoides (Table 2).

As shown in Table 3, the majority (58.4\%) of the students were used stream water for cooking and drinking purpose. This result has been found statistically significant and at higher risk for parasitic 
infection (COR=1.4, 95\% $\mathrm{Cl}=0.474 .15, p=0.001$ ). However, students that used pipe borne water for drinking and cooking activities were found statistically insignificant $(p=0.55)$. Those students who used latrine sometimes were also more likely (2.7 times) at higher risk to get infected with GIH parasites (Table 3). Other independent variables such as hand washing, raw meat eating, shoe wearing habit and finger nail status of the respondents were also assessed; however, none of these parameters were found statistically significant (Table 3).

\section{Discussion}

Although it is neglected disease in the developed world, GIH/STH infections are still remaining the major public health problem in developing countries, particularly in the tropics where appropriate parasitic growth factors exist. As a result, epidemiological study on the prevalence of $\mathrm{GIH} / \mathrm{STH}$ infection in different region of the developing world is a primary objective to identify high-risk communities and formulate appropriate intervention [5, 8-10, 16-19]. In line with this view, the present study attempted to assess the prevalence of different GIH infections in primary school children in Dembi district (southwest Ethiopia).

In the current study, $30.9 \%$ overall prevalence of GIH which have public health importance were identified. Except 7.8\% school children specimen samples showed double infection, most (92.2\%) of the positive samples were identified single infection type. This was comparable with finding from elsewhere in Ethiopia and the world [13, 19-22]. For instance, the helminthic infection prevalence of $27.2 \%$ in Al-Ahsa (Saud Arabia), 31.8\% in western city (Turkey), 34.0\% in Kisumu city (Kenya), 35.6\% in Hintallo-Wejerat (Ethiopia) and 36.5\% Kathmandu valley (Nepal) reports were found to be almost in agreement with the current study (Table 4). However, the current study result has been found much higher $(4.522 .8 \%$ ) than a report from Gondar [5] and Ambo [12] towns in Ethiopia and elsewhere in the world including Taiwan [23], Kenya [17], China [24] and Marshall Islands [25] (Table 4). Still, the present study prevalence was identified lower than study result from Tilili town (44.2\%), Wolaita zone (72.2\%), Azezo town (72.9\%) and Chencha town (81.0\%) in Ethiopia (Table 4). Comparatively, higher helminthic prevalence were also reported in Saud Arabia (45.4\%) El Salvador (53.0\%), Tanzania (57.1\%), India (75.6\%), China (86.0\%), Nigeria (86.2\%) and Malaysia (88.2\%) (Table 4). The possible explanations for the discrepancy between the present and previous study findings might be the result of variation in the geographic location, socioeconomy of the subjects, selection of study participants, sample size, method of parasitological examination, time of the study, access to health care facilities and awareness. Indeed, the comparative result shown in Table 4 is from different geographic locations (Africa, Asia, Middle East, Latin America and Europe) and participants from different population group (pre-/school children, rural community, patients from medical centers and hospitals). The number of participants (sample size) were also varies higher $(n=6976)$ from northern Samar in Philippines [19] and lower $(n=69)$ from Yunnan in southwest China [26].

In this study, a total of six intestinal parasitic worm was detected which could be comparable with study in Nepal [11] that was identified six parasitic worms. As shown in Table 4, our finding was also 
comparable to studies in Ethiopia (five parasites in Ambo town and seven parasites in Wolaita zone and Chencha) and elsewhere in the world (five parasites in Kisumu city, western Kenya and seven parasites in El Salvador). Relatively, small number (three) of parasitic worm infection (Table 4) was reported in Guizhou (southwest China), Peninsular Malaysia and Uttar Pradesh (India). In school children, four intestinal parasitic worms (Table 4) were also reported in Nairobi city (Kenya), Western city (Turkey), Tilili town (Ethiopia) and Yunnan (southwest China). Studies conducted in Saud Arabia [20] and Taiwan [23] were also reported 20 and 13 intestinal parasitic worm species using hospital patient, respectively which was higher than maximum number of parasitic species reported in school children (nine) in Gondar town (north Ethiopia) [5] and Majuro city (Marshall Islands) [25].

The majority of infections in the current and previous studies were single infection types (Table 4). In this study, single infection and double infections were accounted $96.7 \%$ and $2.4 \%$, respectively. Compared to the current study, double infections were significantly higher in school children reported in Chencha town (26.5\%) and Azezo town (47.3\%) in Ethiopia, Makoko urban slum (45.7) and southwest (39.2\%) in Nigeria, Nairobi city (33.3\%) in Kenya, Majuro city (22.4\%) in Marshall Islands and Yunnan (52.0\%) in China. Compared to studies carried out with hospital and community participants, double infection has been found higher in most school age children studies (Table 4). This difference might be due to study population, environmental factors, investigation time and diagnosis method. It is obvious that the target population for the community and hospitals participants were at any age group and educational level, which was not true for school age children that have narrow age range and educational level.

In this study, STHs such as $A$. Iumbricoides and hookworm infections were found the major public health problem. The prevalence of $A$. lumbricoides among school children in the current study area was found to be $43.3 \%$. This prevalence of $A$. lumbricoides was higher than the national prevalence estimate (37\%) in Ethiopia [7] and reports from other parts of the country such as $7.5 \%$ in northwest [5] and $28.9 \%$ south Gondar [33], 23.6\% in Jimma [34], and 37.2\% in Bushulo village [35]. Lower prevalence value of $A$. lumbricoides also reported in Kenya [21] and Malaysia [32] with a prevalence of $4.9 \%$ and $23.8 \%$, respectively. However, the current study $A$. lumbricoides prevalence result was much lower than a report from Wondogent (83.3\%) [36] and Chencha town (60.5\%) [9] in Ethiopia, Nigeria (57.2\%) [30] and Nepal (57.9\%) [18]. There are several studies that mentioned STHs vary among localities due to variations in geographic location, socio-economic conditions and hygienic condition of the population under consideration. Of course, the higher prevalence of $A$. lumbricoides in the current study than the national estimates and elsewhere could be due to lack of drinking water source and latrine usage, which has been found significantly (Table 3) associated with STH infection in the current study area. Compared with sources of drinking water, students using stream water for drinking and food preparation have found a statistical significant difference for STHs than students using pipe water for similar purpose. This supports that the transmission of $A$. lumbricoides infection which is contracted through ingesting embryonic egg through water and food [1]. In terms of gender, male students were identified more prevalent for $A$. lumbricoides than female students, which could be due to boys playing on soil and prefer to eat their food without proper hand washing (Table 2). Moreover, lower age (5 8 years) groups were found more prevalent to for $A$. Iumbricoides than higher age groups (Table 2), which agrees with other 
studies that said lower age groups are more affected than higher age groups [16, 32]. As reported in other studies [1, 16], latrine usage has been found a significant risk factor for STH including A. lumbricoides (Table 3).

The prevalence of hookworm infection among primary school children of Dembi district was identified $26.7 \%$, which is higher than the national hookworm infection prevalence $(16.0 \%)$ in Ethiopia [7]. The prevalence of this helminthic infection was also higher than a report from different areas of Ethiopia and other countries including $4.9 \%$ in Gamo area, south Ethiopia [37] and $12.9 \%$ in south Gonder [33], 6.1\% in Kenya [21] and $17.8 \%$ in Nigeria [30]. Infection by hookworm was much lower when compared to a report from southeastern Ethiopia [14] and Philippines [19] which revealed $60.5 \%$ and $28.4 \%$, respectively. In fact, hookworm disease caused by two worm species (Ancylostoma duodenale and Necator americanus) has been reported one of the most common infections in SSA which affects around 198 million people in the region $[4,6]$. It causes iron deficient anemia and protein malnutrition [1]. Compared to age groups, hookworm infection has been found highest for older age groups ( $>12$ years) than lower age groups (Table 2), which agrees with other studies [6, 26, 31]. For instance, Hotez and Kamath [6] mentioned that hookworm infection has steadily raised in the intensity during late childhood with either a peak or a plateau in adulthood.

The overall prevalence of T. trichiura, Teania species (6.7\%), S.stercoralis (3.3\%) and H.nana (3.3\%) were found to be relatively very low. Interestingly, T. trichiura which is estimated $24 \%$ among STHs infection prevalence in Ethiopia from SSA prevalence proportion [4, 6], is found to be much lower (8.9\%) among school children in Dembi district. This prevalence has also been lower than the previous school (23.1\%) and community (57\%) based study in Jimma/Ethiopia [34] and Peninsular Malaysia [32], respectively suggesting that relatively better toilet facilities, good hand washing habit and better awareness about health in the current study area.

\section{Conclusions}

Findings from this study revealed that GIH particularly STH infections were higher among the primary school children of Dembi district. The most prevalent parasite was A. lumbricoides and hookworm. Although the proportion was very low, T. trichuira, S. stercoralis, Teania species and H. nana were also detected in the stool sample. Males were highly affected sex by GIH than females. Infection rate of GIH was generally higher among age group 58 years than older groups. However, among STH the prevalence of hookworm infection was increased with an increased age group. Absence of safe water supply in the school as well as in the community led to higher prevalence of $\mathrm{GIH}$ infection among school children. Moreover, latrine usage habit was also a significant risk factor for GIH infection.

\section{Abbreviations}

Cl: confidence interval; GIH: gastrointestinal helminth; OR: odds ratio; Ref: reference; SPSS: statistical package for the social sciences; SSA: sub-Saharan Africa; STH: soil transmitted helminth, 


\section{Declarations}

\section{Acknowledgments}

The authors would like to thank all of the study participants, teachers and directors of the selected primary schools for their participation and unreserved support during data collection. We would also like to extend our special thanks to Megersa Olani and Andualem Tamiru for their technical support during preparation and examination of direct wet-mount and concentration technique for stool examination.

\section{Funding}

Not special funding was required for this study.

\section{Availability of data and material}

The data sets in this study are available from the corresponding author on reasonable request.

\section{Authors' contribution}

AG participated in the design of this study, wrote the manuscript, interpreting the results and discussion. AW participated in the design of this study and collect data. AW and WL participated in revising the manuscript. All authors read and approved the final manuscript.

\section{Ethics approval and consent to participate}

This study was reviewed and ethically approved by the Ethics Review Committee on Health Research, Arba Minch University. Permission to conduct the study was also obtained from Dembi Woreda Health Office, Educational Bureau and School Principals. Before the investigation was performed, the purpose of the study was explained to the school principal, laboratory technician, students and parents. The stool sample was collected after obtaining written consent from parents/guardians and assent from children participated in the study. Positive individuals for GIH infections referred to Dembi Health Center for proper treatment of cases and delivering health education for students and parents.

\section{Consent for publication}

Not applicable. 


\section{Competing interest}

The authors declare that they have no competing interests.

\section{Authors' detail}

${ }^{1}$ Department of Biology, College of Natural Sciences, Arba Minch University, P.O. Box 21, Arba Minch, Ethiopia; ${ }^{2}$ Key Laboratory of Environmental Biotechnology Research Center for Eco-Environmental Sciences, Chinese Academy of Sciences, Beijing 100085, PR China.

\section{References}

1. WHO. Helminth control in school-age children: A guide for Managers of Control Programmes. $2^{\text {nd }}$ ed. Geneva: World Health Organization; 2011.

2. Bethony J, Brooker S, Albinico M, Geiger S, Loukas A, Diemert D, Hotez P. Soil-transmitted helminth infections: Ascariasis, trichuriasis, and hookworm. Lancet. 2006; 367:1521-1532.

3. Brooker S, Michael E. The potential of geographical information systems and remote sensing in the epidemiology and control of human helminth infection. Adv Parasitol. 2000; 47:245-288.

4. Deribe K, Meribo K, Gebre T, Hailu A, Ali A, Aseffa A, Davey G. The burden of neglected tropical diseases in Ethiopia, and opportunities for integrated control and elimination. Parasit Vectors. 2012; $5: 240$.

5. Amare B, Ali J, Moges B, Yismaw G, Belyhun Y, Gebretsadik S, Woldeyohannes D, Tafess K, Abate E, Endris M, Tegabu D, Mulu A, Ota F, Fantahun B, Kassu A. Nutritional status, intestinal parasite infection and allergy among school children in Northwest Ethiopia. BMC Pediatr. 2013; 13:7.

6. Hotez P, Kamath A. Neglected tropical diseases in sub-saharan Africa: Review of their prevalence, distribution and disease burden. PLoS Negl Trop Dis. 2009; 3:e412.

7. Tadesse Z, Hailemariam A, Kolaczinski J. Potential for integrated control of neglected tropical diseases in Ethiopia. Trans R Soc Trop Med Hyg. 2008; 102:213-214.

8. Abera A, Nibret E. Prevalence of gastrointestinal helminthic infections and associated risk factors among schoolchildren in Tilili town, Northwest Ethiopia. Asian Pac J Trop Med. 2014; 7:525-530.

9. Abossie A, Seid M. Assessment of the prevalence of intestinal parasitosis and associated risk factors among primary school children in Chencha town, Southern Ethiopia. BMC Public Health. 2014; 14:166.

10. Alemayehu B, Tomass Z, Wadilo F, Leja D, Liang S, Erko B. Epidemiology of intestinal helminthiasis among school children with emphasis on Schistosoma mansoni infection in Wolaita zone, Southern Ethiopia. BMC Public Health. 2017; 17:587

11. Endris M, Lemma W, Belyhun Y, Moges B, Gelaw A, Anagaw B, Alemayehu M, Amare B, Ali J, Birhan W, Teklu T, G/tsadik T, Worku L, Aemiro M, Wassie B, Walle G, Delelegn M. Prevalence of intestinal 
parasites and associated risk factors among students of Atse Fasil general elementary school Azezo, Northwest Ethiopia. Ethiop J Health Biom Sci. 2010; 3:25-33.

12. Samuel F, Demsew A, Alem Y, Hailesilassie Y. Soil transmitted helminthiasis and associated risk factors among elementary school children in Ambo town, Western Ethiopia. BMC Public Health. 2017; 17:791.

13. Tadesse D, Tsehaye A. Impact of irrigation on the prevalence of intestinal parasite infections with emphasis on schistosomiasis in Hintallo-Wejerat, North Ethiopia. Ethiop J Health Sci. 2008; 18:33-38.

14. Mengistu L, Berhanu E. Prevalence of intestinal parasites among school children in a rural area close to the Southeast of Lake Langano, Ethiopia. Ethiop J Health Dev. 2004; 18:116-120.

15. Daniel W, Cross CL. Biostatistics: A Foundation for Analysis in Health Sciences. $10^{\text {th }}$ ed. John Willey and Sons. Inc: United States of America; 2013.

16. Ganguly S, Barkataki S, Karmakar S, Sanga P, Boopathi K, Kanagasabai K, Kamaraj P, Chowdhury P, Sarkar R, Raj D, James L, Dutta S, Sehgal R, Jha P, Murhekar M. High prevalence of soil-transmitted helminth infections among primary school children, Uttar Pradesh, India. Infect Dis Poverty. 2017; 6:139.

17. Mwanthi MA, Kinoti M, Migiro PS, Kinoti M, Ndonga M. Prevalence of intestinal worm infections among primary school children in Nairobi City, Kenya. East Afr J Public Health. 2008; 5:86-89.

18. Rai SK, Uga S, Ono K, Rai G, Matsumura T. Contamination of soil with helminth parasite eggs in Nepal. Southeast Asian J Trop Med Public Health. 2000; 31:388-393.

19. Ross AGP, Olveda RM, McManus DP, Harn DA, Chy D, Li Y, Tallo V, Ng SK. Risk factors for human helminthiases in rural Philippines. Int J Infect Dis. 2017; 54:150-155.

20. Al-Mohammed HI, Amin TT, Aboulmagd E, Hablus HR, Zaza BO. Prevalence of intestinal parasitic infections and its relationship with socio-demographics and hygienic habits among male primary schoolchildren in Al-Ahsa, Saudi Arabia. Asian Pac J Trop Med. 2010; 3:906-912.

21. Odiere MR, Opisa S, Odhiambo G, Jura WGZO, Ayisi JM, Karanja DMS, Mwinzi PN. Geographical distribution of schistosomiasis and soil-transmitted helminths among school children in informal settlements in Kisumu City, Western Kenya. Parasitology. 2011; 138:1569 - 1577.

22. Okyay P, Ertug S, Gultekin B, Onen $\mathrm{O}$, Beser E. Intestinal parasites prevalence and related factors in school children, a Western City sample-Turkey. BMC Public Health. 2004; 4:64.

23. Hsieh MH, Lin WY, Dai CY, Huang JF, Huang CK, Chien HH, Wang CL, Chung WL, Wu JR, Chen ER, Ho CK, Yu ML. Intestinal parasitic infection detected by stool examination in foreign laborers in Kaohsiung. Kaohsiung J Med Sci. 2010; 26.

24. Wang X, Zhang L, Luo R, Wang G, Chen Y, Medina A, Eggleston K, Rozelle S, Smith DS. Soil transmitted helminth infections and correlated risk factors in preschool and school aged children in rural Southwest China. PLoS One. 2012 7:e45939.

25. Liao CW, Chuang TW, Huang YC, Chou CM, Chiang CL, Lee FP, Hsu YT, Lin JW, Briand K, Tu CY, Fan CK. Intestinal parasitic infections: Current prevalence and risk factors among schoolchildren in 
capital area of the Republic of Marshall Islands. Acta Trop. 2017; 176:242-248.

26. Yap P, Du ZW, Chen R, Zhang LP, Wu FW, Wang J, Wang XZ, Zhou H, Zhou XN, Utzinger J, Steinmann P. Soil-transmitted helminth infections and physical fitness in school-aged Bulang children in Southwest China: Results from a cross-sectional survey. Parasit Vectors. 2012; 5:50.

27. Amer $\mathrm{OH}$, Ashankyty IM, Haouas NAS. Prevalence of intestinal parasite infections among patients in local public hospitals of Hail, Northwestern Saudi Arabia. Asian Pac J Trop Med. 2016; 9:44-48.

28. Corrales LF, Izurieta R, Moe CL. Association between intestinal parasitic infections and type of sanitation system in rural El Salvador. Trop Med Int Health. 2006; 11:1821-1831.

29. Mazigo HD, Ambrose EE, Zinga M, Bahemana E, Mnyone LL, Kweka EJ, Heukelbach J. Prevalence of intestinal parasitic infections among patients attending Bugando Medical Centre in Mwanza, Northwestern Tanzania: A retrospective study. Tanz J Health Res. 2010; 12:178-182.

30. Agbolade OM, Agu NC, Adesanya OO, Odejayi AO, Adigun AA, Adesanlu EB, Ogunleye FG, Sodimu AO, Adeshina SA, Bisiriyu GO, Omotoso OI, Udia KM. Intestinal helminthiases and schistosomiasis among school children in an urban center and some rural communities in Southwest Nigeria. Korean J Parasitol. 2007; 45:233-238.

31. Gyang VP, Chuang TW, Liao CW, Lee YL, Akinwale OP, Orok A, Ajibaye O, Babasola AJ, Cheng PC, Chou CM, Huang YC, Sonko P, Fan CK. Intestinal parasitic infections: Current status and associated risk factors among school aged children in an archetypal African urban slum in Nigeria. J Microbiol Immunol. 2017; 52:106-113.

32. Anuar TS, Salleh FM, Moktar N. Soil-transmitted helminth infections and associated risk factors in three Orang Asli Tribes in Peninsular Malaysia. Sci Rep. 2014; 4:4101

33. Jemaneh L. Soil transmitted helminth infections and Shistosoma mansoni in school children from Chilga district, Northwest Ethiopia. Ethiop J Health Sci. 2000; 11:79-85.

34. Tefera E, Belay B, Mekonnen SK, Zeynudin A, Belachew T. Prevalence and intensity of soil transmitted helminths among school children of Mendera Elementary School in Jimma, Southwest Ethiopia. Pan Afr Med J. 2017; 27:88.

35. Terefe A, Shimelis T, Mengistu M, Hailu A, Erko B. Schistosomiasis mansoni and soil-transmitted helminthiasis in Bushulo Village, Southern Ethiopia. Ethiop J Health Dev. 2011; 25:46-50.

36. Berhanu E, Medhin G. Human helminthiasis in Wondogenet, Southern Ethiopia emphases on geohelminthiasis. Ethiop Med J. 2003; 41:333-344.

37. Wegayehu T, Tsalla T, Seifu B, Teklu T. Prevalence of intestinal parasitic infections among highland and lowland dwellers in Gamo Area, South Ethiopia. BMC Public Health. 2013; 13:151.

\section{Tables}

Table 1 Prevalence of soil transmitted helminth infections among sex and age groups 


\begin{tabular}{|c|c|c|c|c|c|c|c|c|}
\hline \multirow[b]{2}{*}{ riables } & \multirow[b]{2}{*}{ Categories } & \multicolumn{2}{|c|}{ Total } & \multicolumn{2}{|c|}{ Infection [n(\%)] } & \multirow[b]{2}{*}{ COR } & \multirow[b]{2}{*}{$95 \%$ CI } & \multirow[b]{2}{*}{$p$-value } \\
\hline & & No & $\%$ & Positive & Negative & & & \\
\hline \multirow[t]{2}{*}{$\mathrm{x}$} & Male & 145 & 49.8 & $55(37.9)$ & $90(62.1)$ & 2.0 & 1.173 .22 & $0.011 *$ \\
\hline & Female & 146 & 50.2 & $35(24.0)$ & $111(76.0)$ & Refn & Refn & Refn \\
\hline \multirow[t]{3}{*}{ e (year) } & 58 & 82 & 28.2 & $33(40.2)$ & $49(59.8)$ & 1.2 & 0.230 .80 & $0.007 *$ \\
\hline & 912 & 89 & 30.6 & $30(33.7)$ & $59(66.3)$ & 0.6 & 0.311 .06 & 0.074 \\
\hline & $\geq 13$ & 120 & 41.2 & $27(22.5)$ & $93(77.5)$ & Refn & Refn & Refn \\
\hline and total & - & 291 & 100 & $90(30.9)$ & $201(69.1)$ & - & - & - \\
\hline
\end{tabular}

Numbers in parenthesis bracket indicates percentage value, OR=Crude odds ratio, CI=Confident interval, Refn=Reference, $*=$ Significant at $95 \%$

Table 2 Prevalence of single and multiple helminth infections among sex and different age groups

\begin{tabular}{|c|c|c|c|c|c|c|c|c|c|c|c|c|c|}
\hline \multirow[t]{3}{*}{ Parasite species } & & \multirow{2}{*}{\multicolumn{2}{|c|}{ Total }} & \multicolumn{4}{|c|}{ Sex $(n=90)$} & \multicolumn{6}{|c|}{ Age groups $(\mathrm{n}=90)$} \\
\hline & & & & \multicolumn{2}{|c|}{ Male } & \multicolumn{2}{|c|}{ Female } & \multicolumn{2}{|c|}{58 years } & \multicolumn{2}{|c|}{$\begin{array}{c}912 \\
\text { years }\end{array}$} & \multicolumn{2}{|c|}{$\begin{array}{c}\geq 13 \\
\text { years }\end{array}$} \\
\hline & & No & $\%$ & No & $\%$ & No & $\%$ & No & $\%$ & No & $\%$ & No & $\%$ \\
\hline Ascaris lumbricoides & & 39 & 43.3 & 22 & 56.4 & 17 & 43.6 & 23 & 59.0 & 6 & 15.4 & 10 & 25.6 \\
\hline Hookworm & & 24 & 26.7 & 12 & 50.0 & 12 & 50 & 4 & 16.7 & 9 & 37.5 & 11 & 45.8 \\
\hline Trichuris trichiura & & 8 & 8.9 & 6 & 75.0 & 2 & 25 & 2 & 25.0 & 5 & 62.5 & 1 & 12.5 \\
\hline Strongliodes stercoralis & & 3 & 3.3 & 3 & 100 & 0 & 0 & 2 & 66.7 & 1 & 33.3 & 0 & 0 \\
\hline Hymenolepis nana & & 3 & 3.3 & 2 & 66.7 & 1 & 33.3 & 0 & 0 & 0 & 0 & 3 & 100 \\
\hline Teania species & & 6 & 6.7 & 6 & 100 & 0 & 0 & 0 & 0 & 5 & 83.3 & 1 & 16.7 \\
\hline $\begin{array}{ll}\text { Ascaris } & \text { lumbricoides } \\
\text { hookworm } & \end{array}$ & + & 7 & 7.8 & 4 & 57.1 & 3 & 42.9 & 2 & 28.6 & 4 & 57.1 & 1 & 14.3 \\
\hline Total & & 90 & 100 & 55 & 61.1 & 35 & 38.9 & 33 & 36.7 & 30 & 33.3 & 27 & 30 \\
\hline
\end{tabular}

Table 3 Bivariate logistic regression analysis of factors associated with STH infections 


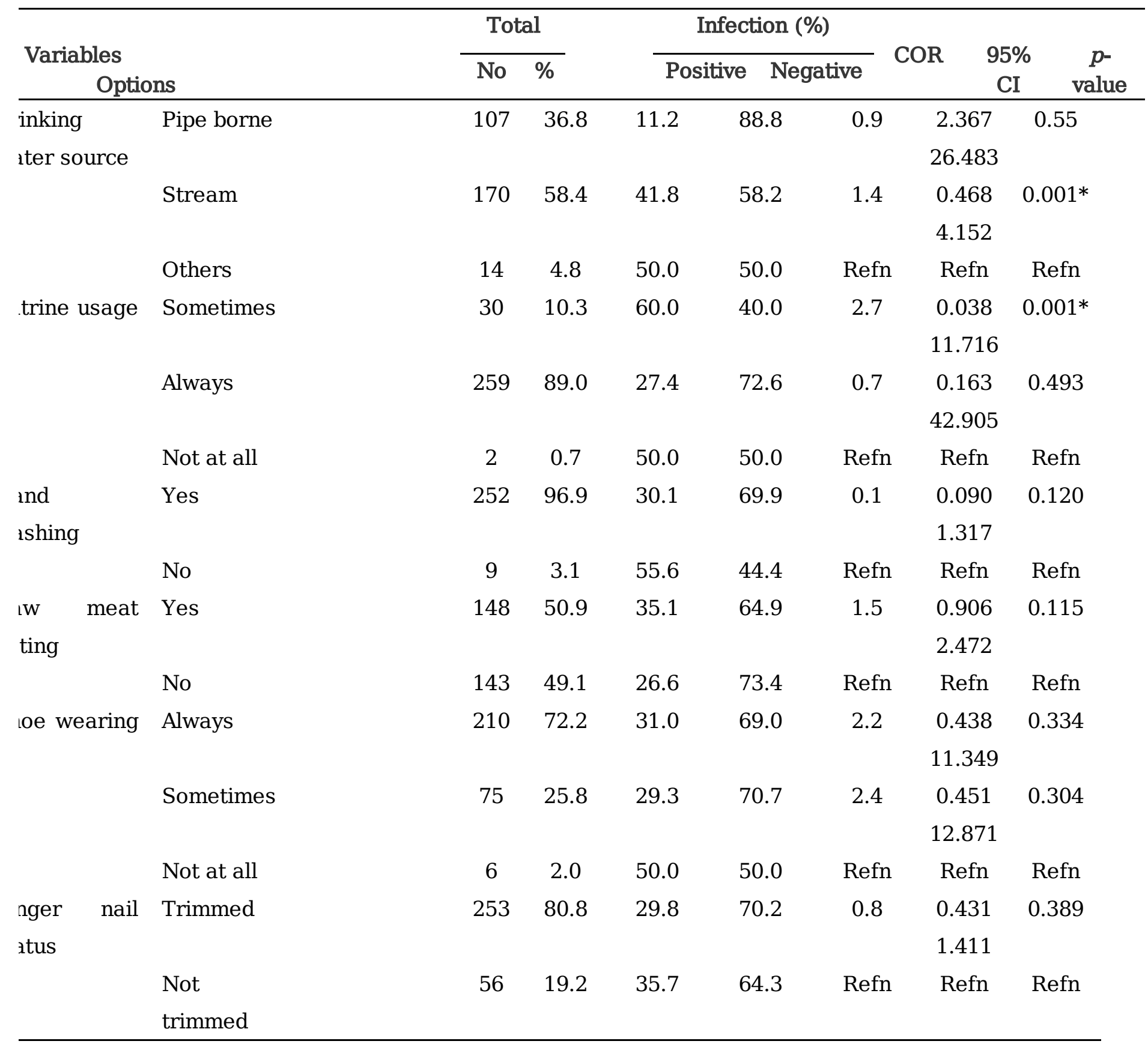

$\mathrm{COR}=$ Crude odd ratio, $\mathrm{CI}=$ Confident interval, $\mathrm{n}=$ Number of samples, Refn=Reference, $*=$ Significant at $95 \%$

Table 4 Comparing helminthic parasitic worm for this study with other studies 


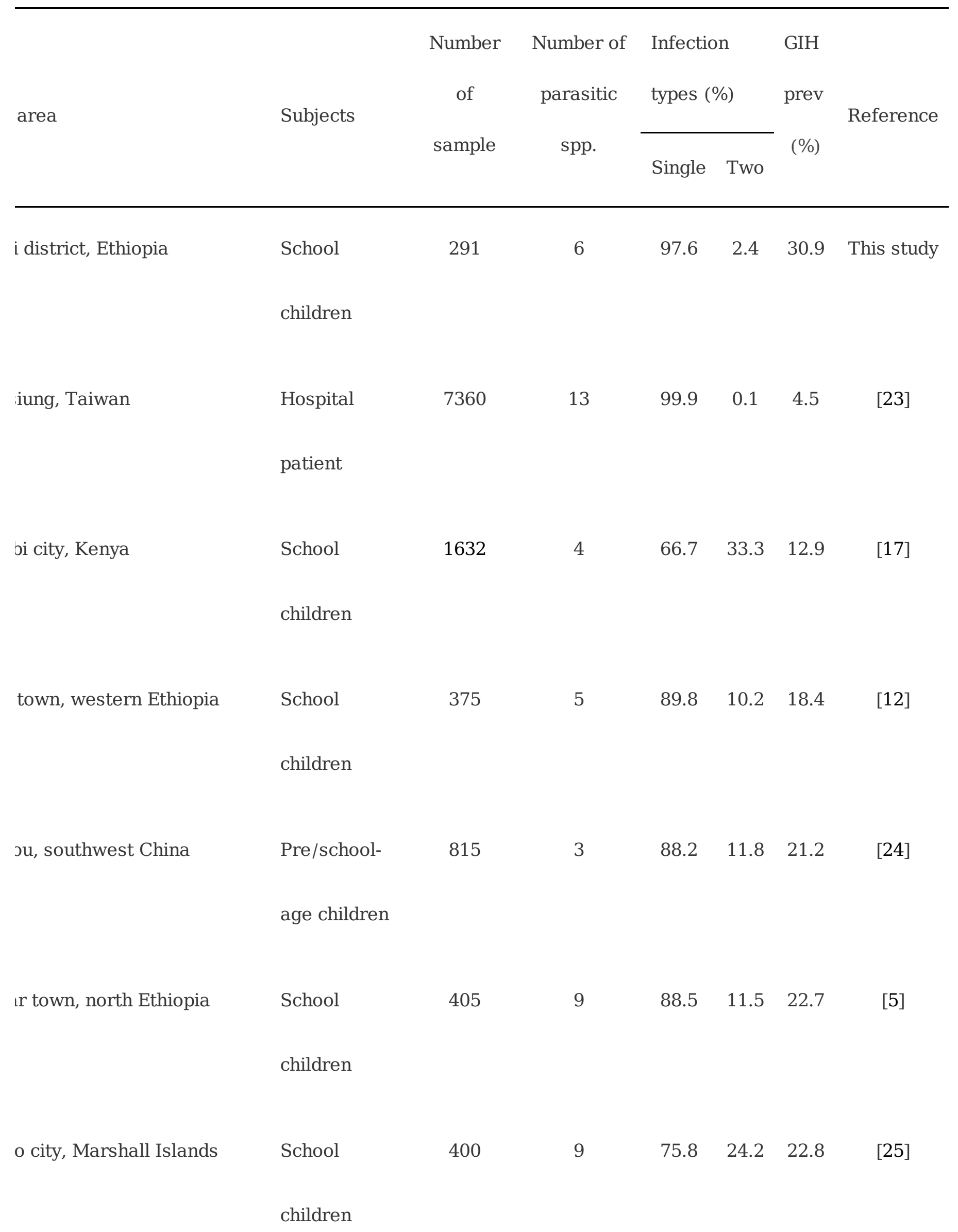



a, Saud Arabia
School
1298
7
$95.7 \quad 4.3 \quad 27.2$
[20]
children

rn city, Turkey

School

456

4

$\begin{array}{lll}80.0 & 20.0 & 31.8\end{array}$

[22]

children

u city, western Kenya

School

1308

5

$\begin{array}{lll}90.6 & 9.4 & 34.0\end{array}$

[21]

children

lo-Wejerat, Ethiopia

Community

800

10

35.6

[13]

ıandu valley, Nepal

People

156

6

$\begin{array}{lll}77.2 & 22.8 \quad 36.5\end{array}$

[18]

in/outside

valley

own, Ethiopia

School

385

4

90.8

9.244 .2

[8]

children

western, Saud Arabia

Hospital

130

20

$92.3 \quad 7.7 \quad 45.4$

[27]

patient

vador

Rural

449

7

$57.3 \quad 42.7 \quad 53.0$

[28]

communities

za, North-western Tanzania Patient in

3152

$\begin{array}{llll}8 & 100 & 0 & 57.1\end{array}$

[29] 
medical

center

west Nigeria

School

1059

8

$\begin{array}{lll}60.8 & 39.2 \quad 66.2\end{array}$

[30]

children

$\begin{array}{cccccccc}\text { sa zone, southern Ethiopia } & \text { School } & 503 & 7 & 100 & 0 & 72.2 & {[10]} \\ & \text { children }\end{array}$

town, northwest Ethiopia

School

354

12

$\begin{array}{lll}52.7 & 47.3 & 72.9\end{array}$

[11]

children

ern Samar, Philippines

Rural

6976

4

$\begin{array}{lll}100 & 0 & 75.6\end{array}$

[19]

communities

Pradesh, India

School

6421

3

$91.9 \quad 8.1 \quad 75.6$

[16]

children

:ha town, southern Ethiopia

School

400

7

$\begin{array}{lll}73.5 & 26.5 \quad 81.0\end{array}$

[9]

children

n, southwest China

School-aged

69

4

$\begin{array}{lll}48 & 52.0 \quad 86.0\end{array}$

[26]

children

so urban slum, Nigeria

School

384

8

$54.3 \quad 45.7 \quad 86.2$

[31] 


\section{children}

sular Malaysia

Community

500

3

100

$0 \quad 88.2$

[32]

= Data not reported, GIH prev=Gastrointestinal helminths prevalence 